\title{
SOSIALISASI PENCEGAHAN STUNTING MELALUI PENYULUHAN DAN PEMBERIAN MAKANAN TAMBAHAN KEPADA IBU HAMIL
}

\author{
Romadona Fatimah Dewi'), Very Kusuma Ningtyas'), Anisah Nasih Zulfa²), Farrah Farandina2), \\ Vivi Nuraini1) \\ 1)Fakultas Teknologi dan Industri Pangan, Universitas Slamet Riyadi Surakarta, Surakarta, Jawa Tengah, Indonesia \\ ${ }^{2)}$ Fakultas Keguruan IImu Pendidikan, Universitas Slamet Riyadi Surakarta, Surakarta, Jawa Tengah, Indonesia \\ Corresponding author : Vivi Nuraini \\ E-mail : Nurainivivi@gmail.com
}

Diterima 18 November 2021, Direvisi 29 November 2021, Disetujui 29 November 2021

\begin{abstract}
ABSTRAK
Masalah stunting menjadi isu penting yang harus diselesaikan secara bersama-sama. Faktor kemiskinan dan pengetahuan yang rendah menjadi faktor utama yang harus dihadapi untuk pencegahan stunting. Pencegahan stunting harus dilakukan sedini mungkin, sejak janin masih di dalam kandungan. Periode 1000 hari pertama anak harus diselamatkan. Untuk menekan jumlah stunting harus ada kerjasama antara pemerintah, dinas kesehatan, dinas sosial dan masyarakat luas. Salah satu cara menekan stunting adalah dengan peningkatan kesadaran stunting melalui sosialisasi dan pendampingan. Pengabdian dilaksanakan oleh tim KKN kelompok 24 yang berkerjasama dengan fakultas teknologi dan industri Pangan Universitas Slamet Riyadi Surakarta serta pemerintah Kelurahan Semanggi. Kelurahan Semanggi kecamatan pasar Kliwon termasuk salah satu Desa dengan angkat stunting tinggi. Pelaksanaan kegiatan dimulai dari FGD. Hasil FGD menunjukkan bahwa bahnya masyarajat Desa Semanggi masih memiliki pengetahuan dan kesadaran yang rendah terhadap penanggulangan bahya stunting. Untuk itu Tim KKN Kelompok 24 memulai kegiatan dengan pendataan dengan tujuan mendapatkan data terbaru jumlah ibu hamil di Kelurahan Semanggi, Hasil pendataan menunjukkan bahwa terdapat 55 ibu hamil yang 34 diantaranya termasuk dalam program keluarga miskin (GAKIN). Setelah pendataan dilanjutkan dengan penyusunan materi, pembuatan video penyuluhan, proses penyuluhan dan terahir evaluasi dan pemberian makanan tambahan untuk ibu hamil. Hasil penyuluhan menunjukkan bahwa ibu hamil menjadi lebih memahami bahaya stunting dan terjadi peningkatan upaya pencegahan dari diri sendiri.
\end{abstract}

Kata Kunci: pencegahan stunting; pemberian makanan tambahan (PMT)

\begin{abstract}
The problem of stunting is an important issue that must be solved together. Poverty and low knowledge are the main factors that must be faced for stunting prevention. Prevention of stunting must be done as early as possible, since the fetus is still in the womb. The period of the first 1000 days of the child must be saved. To reduce the number of stunting, there must be cooperation between the government, health services, social services and the wider community. One way to suppress stunting is to increase awareness of stunting through socialization and mentoring. The service is carried out by a group of 24 KKN team in collaboration with the Faculty of Technology and Food Industry, Slamet Riyadi University, Surakarta and the Semanggi Village government.Semanggi Village, Pasar Kliwon Subdistrict, is one of the villages with high stunting rates. The implementation of activities starts from the FGD. The results of the FGD showed that the people of Semanggi Village still had low knowledge and awareness of stunting prevention. For this reason, the KKN Group 24 Team started activities with data collection with the aim of getting the latest data on the number of pregnant women in Semanggi Village. After data collection, it was continued with the preparation of materials, making counseling videos, the counseling process and finally evaluating and providing additional food for pregnant women. The results of the counseling showed that pregnant women became more aware of the dangers of stunting and there was an increase in self-prevention efforts.
\end{abstract}

Keywords: stunting prevention; supplementary feeding

PENDAHULUAN

Salah satu Pembangunan Berkelanjutan (TPB)/Sustainable Development Goals (SDGs) yang menjadi komitmen global dan nasional dalam upaya untuk menyejahterakan masyarakat mencakup 17 tujuan salah satunya 
adalah kehidupan yang sehat dan sejahtera. Kejadian balita pendek atau biasa disebut dengan stunting merupakan salah satu masalah gizi yang dialami oleh balita di dunia saat ini. Pada tahun 2017, 22,2\% atau sekitar 150,8 juta balita di dunia mengalami stunting. Pada tahun 2017, lebih dari setengah balita stunting di dunia berasal dari Asia (55\%) sedangkan lebih dari sepertiganya (39\%) tinggal di Afrika. Dari 83,6 juta balita stunting di Asia, proporsi terbanyak berasal dari Asia Selatan $(58,7 \%)$ dan proporsi paling sedikit di Asia Tengah (0,9\%). Data Prevalensi balita stunting yang dikumpulkan World Health Organization (WHO) menunjukkan bahwa Indonesia termasuk ke dalam negara ketiga dengan prevalensi tertinggi di regional Asia Tenggara/South-East Asia Regional (SEAR). Rata-rata prevalensi balita stunting di Indonesia tahun 2005-2017 adalah 36,4\% (Situasi Balita Pendek (Stunting) di Indonesia, 2018).

Perilaku sadar gizi sangat penting karena merupakan penyebab langsung dari masalah gizi Indonesia. Secara umum, gizi buruk disebabkan oleh kemiskinan, kekurangan pangan, perilaku gizi rendah, kebiasaan dan faktor lainnya. Demikian pula, kelebihan gizi disebabkan oleh perilaku yang salah. Prevalensi stunting di Jawa Tengah memberikan kontribusi sebanyak $28 \%$ dan menduduki peringkat 9 dari seluruh propinsi di Indonesia. Desa Semanggi menjadi salah satu desa di Jawa Tengah dengan jumlah anak stunting yang cukup tinggi yaitu 9 orang. Hal tersebut perlu penanganan dan pencegahan dengan cepat dan serius untuk menekan angka stunting di Desa Semanggi.

Stunting disebabkan oleh masalah asupan gizi yang dikonsumsi selama kandungan hingga masa balita. Kurangnya pengetahuan ibu mengenai kesehatan dan gizi sebelum masa kehamilan, serta masa nifas, terbatasnya layanan kesehatan seperti pelayanan antenatal, pelayanan post natal dan rendahnya akses makanan bergizi, rendahnya akses sanitasi dan air bersih juga merupakan penyebab stunting (Yuwanti et al., 2021).

Realisasi program kerja yang di lakukan sebagai bentuk pencegahan tersebut adalah melakukan penyuluhan dan pendampingan kepada ibu hamil di Desa Semanggi dengan tujuan meningkatkan keasadaran ibu hamil terhadap kesehatan janin dan bayi. Selain itu, peningkatan pengetahuan ibu hamil juga harus diupayakan baik dari segi pemenuhan gizi sejak dalam kandungan, penerapan pola hidup sehat dan bersih, dan pemenuhan gizi bayi melalui MP-ASI (Makanan Pendamping ASI) .

\section{METODE}

1. Metode Pelaksanaan
Pelaksaan kegiatan pengabdian dilakukan oleh tim KKN kelompok 24 tahun ajaran 2020/2021 yang bekerjasama dengan Fakultas Teknologi dan Industri Pangan Universitas Slamet Riyadi. Pengabdian berfokus pada kegiatan Penyuluhan dengan pelaksanaan yang dilakukan dalam berbagai tahap seperti yang digambarkan pada gambar 1 .

2. Profil Mitra

Kelurahan Semanggi memiliki kondisi geografis dengan ketinggian tanah DPL $\pm 82 \mathrm{~m}$ dengan topografi dataran rendah. Kondisi lingkungan di Kelurahan Semanggi juga tergolong padat penduduk dengan kemamouan ekonomi yang heterogen. Desa semanggi memiliki jumlah penduduk sebanyak 24.274 tetapi dengan pemberdayaan masyakarat yang rendah, ada beberapa bagian desa yang termasuk kawasan kumuh sehingga sulit untuk bisa menerapkah PHBS ( Pola Hidup Sehat dan Bersih).

3. Langkah-langkah Pelaksanaan

a. FGD (Forum Group Discussion)

FGD dilakukan sebelum melakukan kegiatan pengabdian. Hal tersebut bertujuan untuk melakukan diskusi dan interaksi terhadap masyarakat, pemangku kepentingan ( Pemerintah Kecamatan dan Desa), Kader Posyandu, Dinas Kesehatan Kota Surakarta, tim LPPM UNISRI dan kelompok pengabdian.

b. Pendataan

Pendaatan dilaukan agar bias mendapatkan data terbaru sesuai kondisi lapanga karena data yang dimiliki Desasudah tidak representative untuk digunakan. Pendatan dilakukan secara langsung dengan mendatangi warga desa dengan data informasi awal dari Desa dan kader posyandu. Penataan dilaksanakan dengan melibatkan pemangku kepentingan seperti Kader Posyandu, ibu PKK hingga ke pemerintah tingkat RW dan RT. Tujuan lain dari pendataan ini adalah melakukan pengelompokan ibu hamil berdasarkan tingkat pendapatan agar dapat diketahui profil ibu hamil di Desa Semanggi. Selain itu proses pendataan juga dimanfaatkan untuk melakukan wawancara kepada beberapa ibu hamil terkait pengetahuan tentang stuntuing. Hasil wawancara akan digunakan untuk penyusunan materi sosialisasi dan penyuluhan.

c. Penyusunan Materi

Materi yang diberikan diperoleh dari Kementrian Kesehatan yang kemudian 
akan disosialisasikan kepada ibu hamil. Penyusunan materi dilakukan agar ibu hamil dapat menambah wawasan mengenai pentingnya menjaga kesehatan janin. Mtaeri yang diberikan berisi tentang pengenalan stunting, bahaya stunting hingga pencegahannya.

d. Pembuatan dan Deseminasi Video Materi yang telah disusun kemudian dibuat dalam bentuk viedo untuk mempermudah proses pembelajaran kepada ibu hamil.

Video merupakan media elektronik yang

mampu menggabungkan teknologi audio dan visual secara bersama sehingga menghasilkan suatu tayangan yang dinamis dan menarik. Video dapat dikemas dalam bentuk VCD dan DVD sehingga mudah dibawa kemana-mana, mudah digunakan, dapat menjangkau audiens yang luas dan menarik untuk ditayangkan (Yudianto, 2017). Video dibuat iteraktif agar tidak membosankan untuk dilihat dan memungkinkan untuk bias dilihat kembali suatu hari. Pemilihan media video juga didasakan karena tingkat memungkinkan untuk menghadirkan ibu hamil dan membentuk kerumunan, karena masa pandemic sangat rentan untuk ibu hamil.

e. Sosialisasi dan Pemberian PMT

Sosialisasi tentang makanan tambahan dan pemberian makanan tambahan akan dilaksanakan secara luring dengan metode take away agar dapat meminimalisir adanya kerumunan. lbu hamil akan diberikan metari tentang pentingnya pemenuhan gizi ibu hamil dan diberikan makanan tambahan contoh yang baik dikonsumsi oleh ibu hamil. Kegiatan sosialisasi dan pemberian PMT dilakukan dengan dengan protokol kesehatan yang ketat.

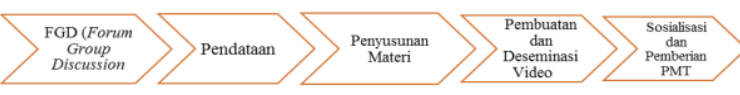

Gambar 1. Alur metode pelaksaaan kegiatan

\section{HASIL DAN PEMBAHASAN \\ 1. Hasil Pelaksaan Kegiatan \\ a. Hasil FGD}

Focus Group Discussion (FGD) dilaksanakan sebelum pelaksaan pengabdian pada tanggal 27 Juli 2021. Tujuan dari pelaksaan FGD adalah untuk mendapatkan titik temu terkait langkah yang harus dilakukan agar tepat sasaran dan solutif dengan masalah yang terjadi di Desa Semanggi. FGD mengundang pemangku kepentingan (Perwakilan Desa dan Kecamatan), Dinas kesehatan, Kader Posyandu, Kader PKK, Ketua LPPM Unisri dan Tim Pengabdian untuk turut serta memberikan paparan dan masukan terkait masalah stunting di Kecamatan Pasar Kliwon.

Tujuan utama metode FGD adalah untuk memperoleh interaksi data yang dihasilkan dari suatu diskusi sekelompok partisipan/responden dalam hal meningkatkan kedalaman informasi menyingkap berbagai aspek suatu fenomena kehidupan, sehingga fenomena tersebut dapat didefinisikan dan diberi penjelasan. Data dari hasil interaksi dalam diskusi kelompok tersebut dapat memfokuskan atau memberi penekanan pada kesamaan dan perbedaan pengalaman dan memberikan informasi/data yang padat tentang suatu perspektif yang dihasilkan dari hasil diskusi kelompok tersebut (Afiyanti, 2008). Hasil FGD mendapatkan kesepakatan bahwa penanganan stunting akan dilaksanakan di Desa Semanggi karena memiliki kasus stunting paling tinggi diantara desa yang lainnya di Kecamatan Pasar Kliwon. Program yang direkomendasikan untuk dilaksanakan yaitu penanganan stunting sejak dalam kandungan, sehingga target pengabdian adalah ibu hamil di Desa Semanggi.
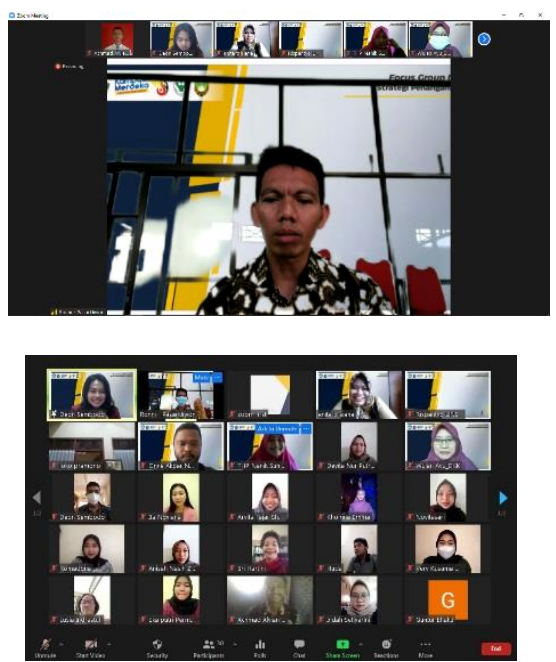

Gambar2. Pelaksanaan Focus Group Discussin (FGD)

b. Pendataan

Kegiatan survei dilakukan untuk mendapatkan data ibu hamil yang terbaru di Kelurahan Semanggi, kegiatan tersebut melibatkan Linmas, Kader Posyandu dan bantuan pemerintah desa Semanggi untuk mempermudah dalam mendapatkan alamat yang akan dituju. Kegiatan survei menghasilkan data bahwa di Kelurahan Semanggi terdapat 55 ibu hamil yang 34 diantaranya termasuk 
dalam program keluarga miskin (GAKIN). Selian pendataan, juga dilakukan wawancara yang memberikan beberapa gambaran tentang ibu hamil di desa semanggi, antara lain :

1. Hasil wawancara dan sampling data menghasilkan data berupa ibu hamil di Kelurahan Semanggi rata-rata merupakan ibu muda dengan umur 22th-30th.

2. Rata-rata kemanilan merupakan kehamilan pertama

3. Lebih dari $50 \%$ ibu hamil yang belum mengetahui bahaya stunting pada anak.

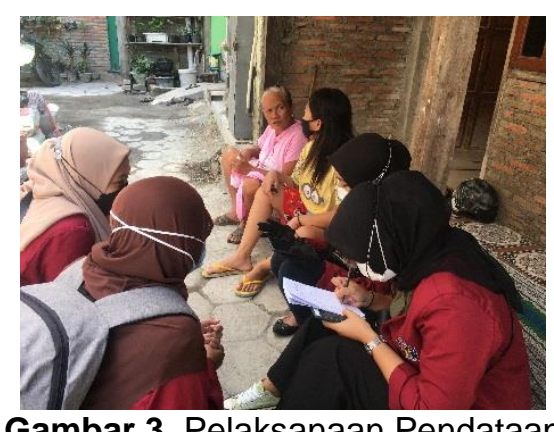

c. Penyusunan Materi

Hasil pendataan dan wawancara dari kegiatan sbelumnya dijadikan bahan pembuatan materi penyuluhan ibu hamil di Desa Semanggi. Materi yang akan diberikan kepada ibu hamil merupakan materi yang diambil dari Kementrian Kesehatan. Materi yang diberikan yaitu tentang penyuluhan ibu hamil yang berisikan isu tentang tingginya Angka Kematian lbu (AKI), Angka Kematian Bayi (AKB), penyebab kematian ibu dan masalah gizi.

Pemberian materi dilakukan dengan dua cara yaitu dengan memberikan print-out dan dengan cara disebar luaskan melalui media youtube. Pemberian print out dilakukan untuk mengantisipasi ibu hamil yang tidak memiliki smartphone dan pemberian materi yang disebar luaskan melalui media youtube berupa video bertujuan agar bermanfaat bagi ibu hamil lain.

d. Pembuatan dan Deseminasi Video Materi tersebut kemudian dibuat dalam sebuah video pendek yang interaktif untuk selanjutnya disebarluaskan ke ibu Hamil di Desa semanggi. Pemilihan video sebagai media penyebaran informasi di dasarkan pada 2 hal. Pertama untuk meminimalisir adanya kerumunan dikarenakan ibu hamil sangat rawan terkait adanya pandemi.
Kedua menurut (Yudianto, 2017) media video merupakan media pembelajaran yang paling tepat dan akurat dalam menyampaikan pesan dan akan sangat membantu pemahaman. Kelebihan media video adalah bisa diputar ulang dan bisa memperlihatkan secara nyata sesuatu yang pada awalnya tidak mungkin bisa dilihat yang akhirnya bisa memicu adanya diskusi (Prastowo, 2012).

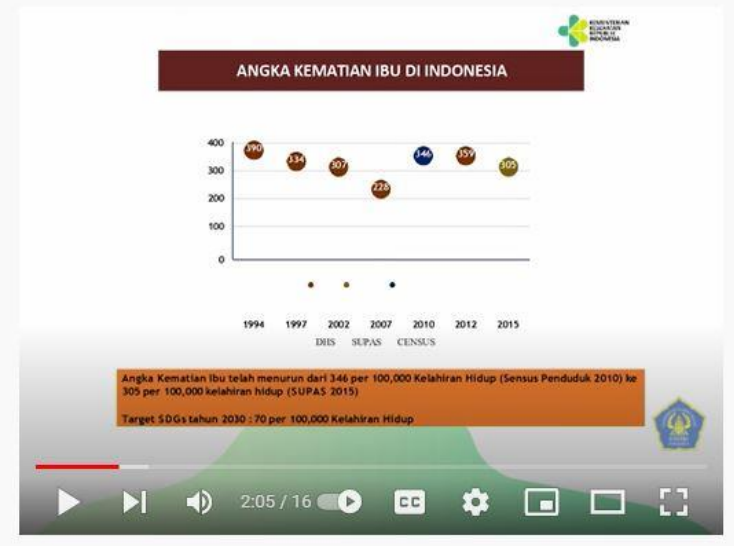

Penyuluhan ibu Hamil

Gambar 4. Materi Penyuluhan untuk ibu Hamil

Video tersebut kemudian disebarluaskan melalui youtube agar dapat diakses ibu hamil di Desa Semanggi. Untuk ibu hamil yang tidak memiliki smart phone tim pengabdian akan melakukan jemput bola kepada target agar materi tetap dapat diterima. Parameter ketercapaian penyebaran video diukur saat sosialisai dan pemberian PMT ( Pemberian Makanan Tambahan)

e. Sosialisasi dan Pemberian PMT Sosialisasi dan pemberian PMT dilaksanakan secara luring dengan metode take away . Ibu hamil yang telah mendapatkan materi penyuluhan melalui video diberikan pertanyaan terkait kepahaman terkait bahaya stunting. Kemudian dilanjutkan sosialisasi singkat tentang contoh bahan makanan yang baik untuk dikonsumsi ibu hamil. Pada sosialisasi yang telah dilakukan, dindapatkan hasil bahwa ibu hamil menjadi lebih paham tentang bahayanya apabila tidak dengan baik menjaga kesehatan janin dan tentang cara pencegahan stunting. Pemberian makanan tambahan (PMT) dilakukan untuk memberi contoh makanan yang baik dikonsumsi ibu hamil. Beberapa contoh makanan yang murah dan mudah 
didapatkan diberikan kepada ibu hamil sebagai contoh makanan baik untuk ibu hamil, antara lain buah buahan ( pisang, avocado, jeruk) yang tinggi asam folat dan juga sayur mayur. Kebiasaan ibu mengkonsumsi sayur saat hamil akan memberi dampak kepada kesukaan anak di masa mendatang. Kebiasaan makan ibu saat hamil memberikan pengaruh terhadap kebiasaan makan anak di usia Balita (Yuwanti et al., 2021). Pemberian makanan tambahan dimaksudkan agar membiasakan ibu hamil bisa menkonsumsi dengan rutin makanan yang murah tapi bergizi baik, seperti yang dicontohkan, meskipun dengan harga yang terjangkau bisa memenuhi kebutuhan gizi ibu hamil.

Selain itu pandemic COVID-19 membuat ibu harus ekstra lebih berhatihati dan pemenuhan gizi harus lebih baik. Pemenuhan gizi di masa kehamilan baik trimester 1, 2 dan 3 dimasa pandemic covid-19 wajib memenuhi akan kebutuhan nutrisi, yang bertujuan untuk peningkatan imunitas ibu hamil itu sendiri maupun janin yang ada dalam kandungannya

Sistem imun dapat ditingkatkan oleh nutrisi yang mendukung dari aneka makanan dan sayur atau buahbuah, antara lain :

1. Vitamin B terdapat di beberapa makanan, buah-buah maupun sayuran seperti ragi, beras, pisang, alpukat, telur, keju, ikan, daging sapi, sayuran, kacang dan lain-lain.

2. Vitamin $\mathrm{C}$ diperlukan untuk meningkatkan daya tahan tubuh dan tidak dapat diproduksi oleh tubuh. Sementara itu, sumber vitamin C alami dapat diperoleh dari buah-buahan yang kaya vitamin $C$ seperti strawberry, kiwi dan buah-buahan sitrus.

3.Sumber dari vitamin A dapat diperoleh antara lain dari minyak ikan, wortel, brokoli, telur, dan susu.

4. Vitamin $D$ penting untuk menjaga kesehatan dan kekuatan tulang dengan membantu absorbsi kalsium di usus. Vitamin $\mathrm{D}$ dapat diperoleh dari paparan sinar matahari, dapat juga diperoleh dari makanan seperti ikan salmon, telur, keju dan produk susu olahan.

5. Vitamin E diantaranya dari buah kiwi, kacang almond, alpukat, telur, susu, dan kacang.

6. Vitamin K umumnya berasal dari sayuran hijau seperti sledri, alpukat dan buah kiwi.

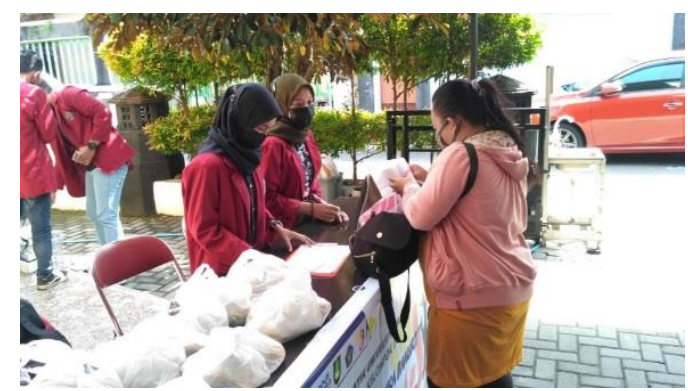

Gambar 5. Pelaksanaan Sosialisasi dan Pemberian PMT

\section{Monitoring Dan Evaluasi}

Monitoring dan evaluasi dilaksanakan menggunakan metode wawancara secara acak saat pemberian PMT. Wawancara dilakukan untuk mengetahui perubahan pengetahuan ibu hamil terhadap bahaya stunting, kemudian bagaimana respon terhadap kesadaran ibu hamil. Hasil monitoring menunjukkan bahwa ibu hamil menjadi lebih memahami bahaya stunting, dan akan berupaya untuk memenuhi kebutuhan gizi bayi dengan lebih baik sejak dalam kandungan.

3. Kendala yang dihadapi dan pemecahan solusi

a. Kendala

1. Kesadaran ibu hamil akan bahaya stunting belum ada karena faktor pengetahuan dan kemampuan keuangan. Masalah yang dihadapi adalah keterlambatan kesadaran tentang bahaya stunting pada ibu hamil padahal usia kandungan sudah masuk trimester ketiga. Disertai dengan ketidakmampuan ibu hamil untuk mengkonsumsi makanan yang bergizi dan mengkonsumsi vitamin yang rutin.

2. Jarak lahir anak sangat dekat, sehingga focus dan perhatian ibu terbagi antara kehamilan dan baduta yang harus diasuh

b. Solusi permasalahan

1. Sosialisasi tentang bahaya stunting dilakukan sebagai syarat administrasi pranikah, sehingga ibu hamil bisa menjaga kehamilan dengan baik sejak trimester awal

2. Pembentukan kebun gizi untuk pemenuhan gizi ibu hamil secara mandiri seperti yang dilakukan (Awaludin, 2019).

3. Pemberian asam volat dan zat besi secara rutin dari puskesmas kepada ibu hamil secara gratis untuk menjaga asupan vitamin ibu hamil dari trimester awal hingga akhir

4. Melakukan sosialisasi KB agar pengaturan jarak lahir anak menjadi 
lebih terencana, sehingga anak akan mendapatkan perhatian yang pemenuhan gizi yang optimal, juge membentuk POKJA (Kelompok Kerja) sebagai wadah informasi bagi masyakat seperti yang telah dilakukan (Tentama et al., 2018).

\section{SIMPULAN DAN SARAN}

Berdasarkan hasil pendataan yang telah dilakukan di desa Semanggi hampir $70 \%$ ibu hamil dengan usia muda yaitu kisaran 22-30th dan hamil anak pertama. Setelah dilakukan sampling dapat disimpulkan ibu-ibu muda masih kurang pengetahuan tentang bahaya stunting pada anak dan angka kematian ibu karena kurangnya sosialisasi tentang ibu hamil yang ada di desa Semanggi. Pendampingan kepada ibu hamil berupa penyuluhan, sosialisasi dan pemberian makanan tambahan meningkatkan pengetahuan dan kesadaran ibu hamil terhadap bahaya stunting.

\section{UCAPAN TERIMAKASIH}

Tim penulis mengucapkan terimakasih kepada warga Kelurahan Semanggi atas antusiasime yang diberikan kepada kami selaku tim KKN-T Kelompok 24 UNISRI. Tim Penulis mengucapkan terimakasih kepada Pemerintah Kelurahan Semanggi yang telah membantu tim KKN-T Kelompok 24 dalam melengkapi datadata yang diperlukan dan memeberikan kami izin untuk melaksanakan pengabdian di Kelurahan Semanggi. Tim penulis mengucapkan terimakasih kepada tim LPPM (Lembaga Pengabdian Pada Masyarakat) UNISRI serta FATIPA (Fakultas Teknik Industri dan Pangan) UNISRI yang membantu pendanaan dalam kegiatan ini. Pengabdian ini didanai dana PKKM (Program Kompetisi Kampus Merdeka) tahun pendanaan 2021.

\section{DAFTAR RUJUKAN}

Afiyanti, Y. (2008). Focus Group Discussion (Diskusi Kelompok Terfokus) sebagai Metode Pengumpulan Data Penelitian Kualitatif. Jurnal Keperawatan Indonesia, 12(1), https://doi.org/10.7454/jki.v12i1.201

Awaludin. (2019). [ Tract: Public Health Nutrition ] [ Analisis Bagaimana Mengatasi Permasalahan Stunting Di Indonesia. Jurnal Kedokteran, 35(4), 60.

Tentama, F., Delfores, H. D. L., Wicaksono, A. E., \& Fatonah, S. F. (2018). Penguatan Keluarga Sebagai Upaya Menekan Angka Stunting Dalam Program Kependudukan, Keluarga Berencana Dan Pembangunan Keluarga (Kkbpk). Jurnal Pemberdayaan: Publikasi Hasil Pengabdian Kepada
Masyarakat, 2(1), https://doi.org/10.12928/jp.v2i1.546

Yudianto, A. (2017). Penerapan Video Sebagai Media Pembelajaran. Seminar Nasional Pendidikan 2017, 234-237.

Yuwanti, Mulyaningrum, F. M., \& Susanti, M. M. (2021). Faktor-Faktor yang Mempengaruhi Stunting pada Balita di Kabupaten Grobogan. Jurnal Keperawatan Dan Kesehatan Masyarakat STIKES Cendekia Utama Kudus, 10(1), 84.

htpp://jurnal.stikescendekiautamakudus.a c.id 